\title{
Recent Advances in Development of Multi Grain Bakery Products: A Review
}

\author{
Sunil Manohar Behera* and P.P. Srivastav
}

Agricultural and Food Engineering Department, Indian Institute of Technology Kharagpur, West Bengal-721302, India

*Corresponding author

\section{A B S T R A C T}

\begin{tabular}{|l|}
\hline Ke y w o r d s \\
$\begin{array}{l}\text { Functional food, } \\
\text { Multi grain, Bakery } \\
\text { products, Bioactive } \\
\text { compounds }\end{array}$ \\
\hline Article Info \\
\hline $\begin{array}{l}\text { Accepted: } \\
\text { 12 April } 2018 \\
\text { Available Online: } \\
\text { 10 May } 2018\end{array}$ \\
\hline
\end{tabular}

In the past few years, the food sectors have shown more attention towards the functional food development. The erudition of the effects of processing as well ingredient composition is essential in order to optimize the conditions and to obtain functional foods affluent in bioactive compounds. Particularly natural antioxidants present in food have received significant interest because of their safety and potential alimental and therapeutic effects. Since way back, bread and bakery products play a predominant role in human nutrition. Numerous cereal related bakery and non-bakery products have been put into engenderment including bread, biscuits, snacks, cookies, noodles, tea, sprouts, and so on. However, a trend has been noticed for an increased need for tastier and nutritionally affluent bakery items prepared with various cereals and plant seeds nowadays. An incipient business has emerged through that demand for companies specialized in the manufacturing of stabilized multigrain bakery products. This review is engrossed on current advances in enriching the bakery products with natural raw materials affluent in bioactive compounds specifically cereals and seeds as well as their overall nutritive value and consumer approval. Conclusively, the long run trends in several multigrain products processing are also addressed.

\section{Introduction}

Last decades, the food sector influences the economy in several nations in relation to the significant contribution for the processing of agricultural raw materials and food supply. In recent years, consumer demands and expectancy in the field of food production have changed impressively. Today foods aren't meant to only satiate hunger and to offer necessary nutrients for humans but additionally to stop nutrition-related diseases and improve psychological and physical wellbeing (Betoret et al., 2011). Thus, the development of new functional foods is one of the most attractive trends in the food market. Functional foods are the ones that exert a scientifically proven specific health benefit beyond their nutritional entity even if the consumption of the specific formulation is not much necessary for human life. A number of the functional foods such as fortified beverages, juices, milk, yoghurts, margarine, cereals, etc. produced nowadays based on the consumer perspective and market demand. 
These products are gaining interest for an increasingly health-concerned society and may be especially relevant for obviating or delaying a number of age-cognate diseases (Giménez-Bastida et al., 2015).

Cereals are the ascendant crops in world agribusiness, and they are the first source of calories and protein to the diets of humans. Now-a-days, cereal-based confectionery products comprise a colossal group of products which differ in composition, production methods and sensory attributes. They are widely accepted and consumed by all categories of consumers, eaten afore and after repasts throughout human lives. Supplementally, they have long shelf-lives which make them convenient for use. They are considered to be a concentrated food due to high contents of carbohydrates, fats and low moisture contents. Therefore, they supply a substantial amount of energy to the diet. Enrichment of foodstuffs with functional elements like cereals and seeds has been commonly utilized so that they can improve their pro-health qualities. In this regards, bakery products are consumed in colossal quantities daily and thus, providing a convenient medium for distributing dietary fibre and other salubrious compounds to consumers. Also, in developed countries, more than $50 \%$ of the total energy intake is from cereal food products (e.g. bread, cookies etc.) emerging them the best vehicle for the functional supplements (Akhtar et al., 2011). To date, the incorporation of bran from different cereals has become the most mundane practice of incrementing dietary fibre in baking, but lately, other sources such as malt and whole grain have made popularity.

Realizing the adversity of these refined products, the enhancement of the nutraceutical prospective of bakery items through fortification has appeared as an incipient trend with some effective tests. Bakery items with raised levels of antioxidants and fibre are in popular requirement because of their positions in the protection and enhancement of health and security against many diseases (Sivam et al., 2012). However, there was very less number of extensive evaluation report enlisted regarding all facets of bakery items enriched with natural resources to boost the nutritional and functional value (Dziki et al., 2014). Thus, this article focused on recent findings and advances in the productions of various bakery product mixed with or without wheat by the addition of cereals and seeds highly rich in bioactive compounds.

\section{Nutritional quality of cereal grains used in bakery products}

The functional and nutritional qualities are the two essential factors that depict the relevance of cereal products as individual foods (Henry et al., 2016). At the same time, the grain must have the qualities required to allow efficient manufacture of a food product with the physical and organoleptic qualities appropriate or appealing to humans. This is the perspective that drives individual's demand yet cereal grains make a critical commitment to both the calories and protein parts of the human diet. Additionally, the composition of cereals also has a significant influence on the health of human being (Henry et al., 2016) as well as a key aspect in imparting the quality of processed products (Qiang et al., 2017). Concisely, the mixed grain (multigrain) products can addressed the above requirement in an efficient manner.

Most of the cases multigrain products like bakery items are prepared with or without wheat flour along with various cereal grains as well as oil seeds. Oats, corn, soy, barley, rye, rice, amaranth, triticale, and buckwheat are most regularly utilized cereals in multigrain bakery products to enhance structure, flavour, texture, nutritional variety and consumer 
acceptability. These cereal grains are the vital resource of carbohydrates, protein, dietary fibre, B vitamins and minerals (Table 1). These are also characterised by their rapid glycaemic responses, and refined ingredients such as sugar and fat. In all cereals feed, the major types of energy arise from starchy part, proteins and to a smaller extent, fats. These cereals additionally incorporate a significant amount of non-digestible cell wall polymers (dietary fibre), minerals, vitamins and phytochemicals in the diet. These nutrients concentration and kinds may vary in different grains. Also, cereals are rich source of B vitamins such as thiamin, riboflavin, and niacin as well contains a significant level of vitamin E (McKevith, 2004).

Likewise, wholegrain cereals are abundant in iron, magnesium, and zinc with a minor quantity of many trace elements like selenium (McKevith, 2004). Additionally, the nonstarch polysaccharides (NSP) considered as insoluble and soluble, are an affluent source in all most all the cereal grains where the insoluble NSP is similar in most cereals with differed water-soluble NSP. The most important water-soluble NSP in wheat, rye, and barley is arabinoxylans while oats are rich in $\beta$-glucans. Comparatively, the levels of $\beta$ glucans and arabinoxylans are higher in barley, oats and rye than wheat $(3-11 \%, 3-7$ $\%, 1-2 \%$ and $<1 \%$, on dry weight respectively) (McKevith, 2004). So as to enhance the nutritional value, the consumer end products should fortify with various cereal grains as much as possible to give a finished result. Thus, the foods abundant in wholegrain and dietary fibre and with sluggish glycaemic values have health-protective effects which triggered the interest in creating a new technological innovation to boost the nutrition profiles of cereal foods, and to regulate physiological activities in consumers (Poutanen et al., 2014).

\section{Bakery products fortified with different}

\section{cereal grains}

In the recent years, the bakery industry focused on developing innovative bakery products by utilizing the health-promoting role of various cereals and seeds. Specifically, the bioactive elements within the cereal flour demonstrated numerous positive effects on health. Therefore, the diversification of different bakery items (bread, cookies, cakes, biscuits) from raw materials with potential functional constituents along with the optimization of process parameters and formulations, and the depiction of end products with regards to sensory and physicochemical properties are obtaining a substantial curiosity. The prevention of noncommunicable diseases, variety in diet and importance of functional foods become the prior focus of the food industry and researchers to continuously enhancing the variety, quality, taste and availability of food products.

\section{Bread enriched with various cereal grains}

Wheat bread is a staple food in the human diet in several nations around the world. The principal constituents of wheat bread are wheat flour, yeast, sugar, and salt. Bread is of two type i.e. leavened or unleavened bread. In leavened bread, the leavening agents (baker's yeast or baking powders) in dough produce carbon dioxide resulting in bread aeration. In contrast, there is no carbon dioxide generation in unleavened bread and resulting in flat and dense bread production (Martins and Ferreira, 2017). However, the inherited factors and the sort of wheat and flour utilized for bread preparation are the key factors for the beneficial effects of bread (Adom et al., 2003).

Bread prepared from regular wheat flour (Triticum aestivum L.) has minimal antioxidant potential compared to the bread 
prepared from wholegrain wheat flour (Gunenc et al., 2013). Hung et al., (2009) reported that the antioxidant activity of the whole grain flour was three times higher than that of white flour. Wheat flour is often mixed with rye (Secale cereale L.) flour to enhance the nutritional quality of rye based bread as rye grains are rich in essential phytochemicals (Bondia-Pons et al., 2009; Zielinski, et al., 2008). Hauswaldet al., (2010) showed that rye bread mixed with whole-wheat flour exhibited high antioxidant potential, B-complex vitamins and dietary fibre with low potential harmful compounds, viz. acrylamide, hydroxymethylfurfural, and furfural.

Oat (Avena sativa L.), despite the fact that is consumed in substantially lower levels globally compared to wheat and rice, is a supplier of numerous compounds which demonstrate its higher antioxidant activity such as phytic acid, vitamin-E (tocopherols), phenolic compounds, and avenanthramides, flavonoids, and sterols (Peterson, 2011; Popa et al., 2012). Brindzova et al., (2009) revealed that wheat bread mixed with oat flour showed a higher antiradical potential.

Flander et al., (2007) showed that oat based bread has nutty, gentle and relaxing flavour. McKechnie (1983) documented that oats enriched bread may be retained fresh for an extended time because of good moisture retention property of oats. It has been reported that the bread staling rate became slow down upon agglomeration of oat starch or oat lecithin with wheat bread (Zhang et al., 1998). Moreover, Dziki et al., (2014) described that oat is highly rich in dietary fibre, $\beta$-glucan which enhance the functional properties of wheat bread.

Holtekjølen et al., (2008) reported that the substitution of wheat flour with $40 \%$ barley (Hordeum vulgare L.) flour caused a significant decrease in free phenolics (up to $23.5 \%$ ) during the baking whilst raising the level of bound phenolics. Meanwhile, the actual assessed antioxidant activities have been comparatively stable throughout the baking process. Mäkinen and Arendt (2012) studied the effects of addition of oat malt in preparation of bread from wheat and barley malt and reported that substitution of oat malt substantially improved the loaf volume and nutritional quality of the developed bread. Škrbić et al., (2009) documented that incorporation of hull-less barley and flakes to white and wholegrain wheat bread elevated the taste as well the intake capacity of selenium and $\beta$ - glucan. Dhingra and Jood (2002) analyzed the consequences of the development composite bread with total fatted soy and defatted soy and barley flour in addition with wheat flour at $5 \%, 10 \%, 15 \%$ and $20 \%$ stages on sensory and nutritional quality. They discovered that replacement of barley flour with complete fat and defatted soy flour up to $15 \%$ triggered the important surge in proteins, total lysine, dietary fibre and $\beta$ glucan content. In the same way, the phytochemical regime, as well as the antioxidant potential of China steamed wheat bread (CSB) together with ingredients of flaxseed and barley hull was analyzed by Hao and Beta (2012). Their research exposed that CSB with barley hull improved the DPPH scavenging activity whilst the enrichment of wheat bread with $1 \mathrm{~g}$ of flaxseed hull extract, the oxygen radical absorbance capacity improved by $67.43 \%$ in comparison to the control bread.

The effects of addition of wholegrain rye flour, barley flour, and oat flakes with refined wheat flour (replacing $60 \%$ ) were investigated by Koletta et al., (2014). They revealed that nutritionally rich composite bread was developed with high in $\beta$ - glucan, dietary fibres, and total phenolic content compared white wheat bread. Serpen et al., (2012) analyzed the outcomes of multigrain (wheat, oat, rye, wheat bran, soybean, maize) recipes on total antioxidant potential in bread. 
The outcomes of their research indicated that all multigrain recipes had greater furosine levels than wheat bread. Moreover, the total antioxidant potential was greater in ABTS assays for oat, rye and maize mixture and in DPPH assays for rye, oat and maize mixture while soybean and wheat bran had the highest value in both the cases. Angioloni and Collar (2011) prepared bread using a combination of oatmeal, rye, buck wheat and wheat flour. The total polyphenols content (TPC) was more in multigrain recipes with increasing replacement percentage by reducing wheat flour material i.e. from $592 \mathrm{mg} / \mathrm{kg}$ to $916 \mathrm{mg} / \mathrm{kg}$. At the same time, they had higher antiradical activity than wheat bread. Ragaee et al., (2011) confirmed the significance of wheat bread fortified with wholemeal wheat, rye, barley and their capability to increase antioxidants and dietary fibres. The assimilation of above flours amplified both the free and bound phenolic values with the elevated antioxidant activity of all the bread combinations.

In the past decades, several studies have been carried out on enrichment wheat bread with pseudo-cereals to enhance the nutritional and functional quality. Sanz-Penella et al., (2013) researched the effects of mixing of whole amaranth (Amaranthus cruentus L.) flour with wheat flour up to $40 \%$ level and analyzed its role as a potential bread-making ingredient. The enrichment of bread with amaranth flour impressively enhanced the protein, crude fibre, fat, and ash contents, simultaneously; enhancement of the phytates due to higher side enrichment inhibited the mineral bioavailability. So they proved that supplementation up to 10-20\% could produce a good quality bread with higher nutritional value. Vogrincic et al., (2010) developed bread by supplementing Tartary buckwheat with wheat flour and they reported that the overall antioxidant capacity increased with increasing percentage of buckwheat. It was found from the results of the study carried out by Lin et al., (2009) that dehusked buckwheat substitution up to $15 \%$ of wheat bread claimed high antioxidant activity and nutrient density. In a similar study (Bojnanska et al., 2009), the buckwheat wholegrain flour was added up to $30 \%$ with wheat flour produced a quite satisfied product with higher consumer acceptability rating. The incorporation of wholegrain buckwheat (Fagopyrum esculentum L.) also enhanced the dough processing quality when added at different proportion. Stokić et al., (2015) developed the buckwheat fortified wheat bread by replacing $50 \%$ of wheat flour with buckwheat wholegrain. They discovered that the nutritional value and antioxidant capacity was fundamentally enhanced in the examination with the wheat bread (2.22 times higher aggregate dietary fibre and 4.29 times higher aggregate phenolics content). They additionally found that there was extensively lessening in total cholesterol and LDLcholesterol, and also the proportion of LDL/HDL cholesterol. Verardo et al., (2018) enriched bread with buckwheat flour at $10 \%$, $20 \%$, and $30 \%$ levels and highlighted the differences between the phenolic composition of crust and crumb as well as flavonols and flavan-3-ols content. They showed that bread enriched with $30 \%$ buckwheat flour increased the free and bound phenolics in crust whereas flavonols and flavan-3-ols content were higher in the crumb. The effect of the addition of pseudo-cereals like buckwheat, amaranth, and quinoa (Chenopodium quinoa L.) at $15 \%$ and $30 \%$ level on antioxidant activity and organoleptic properties were studied by Chlopicka et al., (2012). They demonstrated that the supplementation increased the flavonoids content by 2-4 folds from control wheat bread. They also mentioned that buckwheat at elevated dosages increased the antioxidant activity to 2.36 fold and 3.64 fold evaluated by FRAP and DPPH assay respectively though fuse of amaranth, quinoa. A fascinating future trend has been evolved by 
enrichment of wheat bread with flour from germinated (sprouted) cereals and pseudocereals. Khattak et al., (2007) described that germinated seeds are nutritionally and functionally enhanced materials contrasted to the non- germinated seeds. Alvarez-Jubete et al., (2010) documented the influence of sprouting of amaranth, quinoa, and wheat on polyphenol profile and antioxidant capacity. They revealed that among the greater part of all the sprouted seeds tried; buckwheat sprouts demonstrated the most astounding antioxidant activity. In a recent study, Marti et al., (2018) developed a wheat bread with sprouted wheat flour at $15 \%, 25 \%, 33 \%, 50 \%, 75 \%$, and $100 \%$ levels and evaluated the dough properties as well as baking performance apart from nutritional and sensory characteristics. They revealed that dough with $50 \%$ sprouted wheat flour substitution gave a better baking performance with improved dough development.

\section{Cookies enriched with various cereal grains}

Cookies are well-admired snack item consumed worldwide with a long life-span. In recent years, the quality of cookies has been improved into a manifold by integrating numerous items to the formulation such as vitamins, minerals, soy flour, wheat germ, milk powder and honey. This way, cookies can be used as a protein and fibre rich products. Apart from the nutritional enhancement, maintenance of sensory attributes for consumer acceptability is a key strategy for new product development (Rajiv and Soumy, 2015).

Barley grain is rich in many nutrients, such as dietary fibres (soluble and insoluble), B vitamins, minerals and phenolics which makes it as a popular ingredient in bakery items. Gupta et al., (2011) developed cookies by mixing barley flour into wheat flour at different levels $(10 \%, 20 \%, 30 \%$, and $40 \%)$ and studied their physico- chemical, functional and sensory properties.

They showed that all the formulation had higher fibre, mineral and protein contents as compared to the control bread. Additionally, the fortification of barley improved the colour as well as antioxidant properties and phenolics content. Sharma and Gujral (2014) prepared cookies by replacing white wheat flour with whole grain barley at various levels and evaluated the nutritional, functional properties and baking quality of developed cookies. They found that there was a considerable increment in antioxidant activity (AOA), total phenolic content (TPC), metal chelating activity (MCA), reducing power (RP) and total flavonoid content (TFC) with increasing barley proportion. However, the TPC and TFC value decreasing during the baking process.

A clinical research was carried out by offering cookies enriched with psyllium and oat bran to observe the plasma LDL cholesterol levels in different individuals from Northern Mexico (Romero et al., 1998). It was determined from the research that there was a substantial decrease in the plasma LDL cholesterol levels among both normal and hypercholesterolemic individuals. Baumgartner et al., (2018) enriched wheat cookies with dephytinized oat brans at $0 \%, 7 \%, 14 \%$, and $21 \%$ levels and analyzed the physical, functional and sensory characteristics. They evidenced that fortification of cookies with dephytinized oat brans reduced the phytic acid content appreciably whilst enhancing the amount of dietary fibre, phenolics and antioxidant capacity compared to untreated oat bran. 
Table.1 Nutritional composition of some selected cereals (www.glnc.org.au)

\begin{tabular}{|c|c|c|c|c|c|c|c|c|c|c|c|c|c|c|c|c|c|c|c|}
\hline $\begin{array}{l}\text { Per } 100 g \text { dry } \\
\text { weight }\end{array}$ & 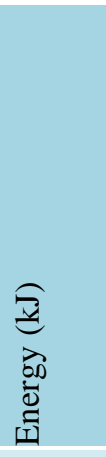 & 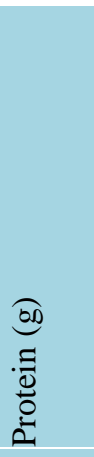 & 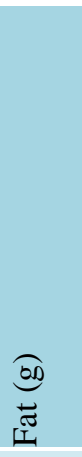 & 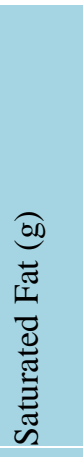 & 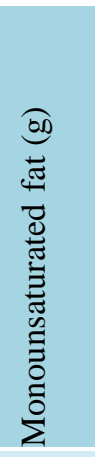 & 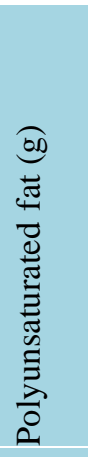 & 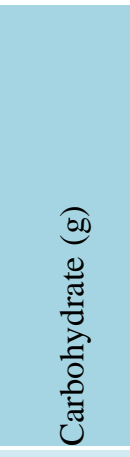 & 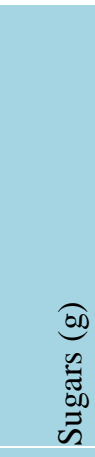 & 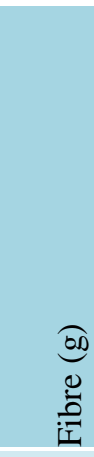 & 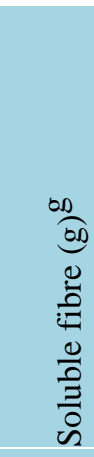 & 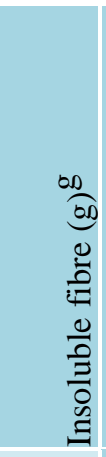 & $\begin{array}{l}3 \\
\vdots \\
\vdots \\
\vdots \\
8\end{array}$ & 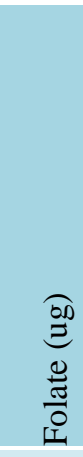 & 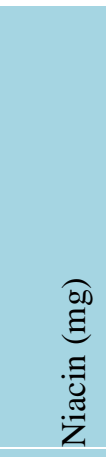 & 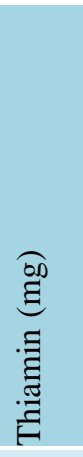 & 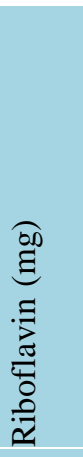 & $\begin{array}{l}\text { OD } \\
\Xi \\
\Xi \\
\Xi \\
\Xi\end{array}$ & 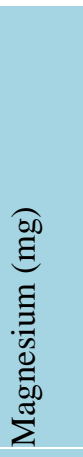 & $\begin{array}{l}\text { OD } \\
\Xi \\
0 \\
: \Xi\end{array}$ \\
\hline Oats & 1572 & 11.0 & 8.7 & 1.6 & 3.5 & 3.1 & 58.1 & 0.0 & 8.9 & 4.9 & 4.0 & 7 & 18 & 1.1 & 0.5 & 0.1 & 3.7 & 131 & 1.9 \\
\hline Brown Rice & 1537 & 7.2 & 2.4 & 0.4 & 0.8 & 0.8 & 76.5 & 0.7 & 3.5 & 0.1 & 3.4 & 5 & 44 & 4.5 & 0.3 & 0.0 & 1.2 & 119 & 2.1 \\
\hline White Rice & 1469 & 6.3 & 0.5 & 0.0 & 0.0 & 0.0 & 78.8 & 0.2 & 2.3 & 0.1 & 2.2 & 5 & 10 & 2.0 & 0.1 & 0.0 & 0.7 & 34 & 1.1 \\
\hline Millet & 1489 & 11.1 & 4.2 & 0.7 & 0.8 & 2.1 & 63.3 & 0.4 & 8.5 & - & - & 5 & 85 & 4.7 & 0.4 & 0.3 & 3.0 & 114 & 1.7 \\
\hline Wheat & 1278 & 13.4 & 1.4 & 0.2 & 0.2 & 0.6 & 60.1 & 0.96 & 12.0 & 1.6 & 10.5 & 4 & 51 & 1.9 & 0.3 & 0.1 & 11.0 & 110 & 5.6 \\
\hline Maize & 1289 & 6.9 & 3.4 & 0.4 & 0.7 & 1.4 & 62.8 & 2.3 & 10.1 & 1.1 & 9.0 & 3 & 26 & 3.5 & 0.2 & 0.1 & 6.0 & 133 & 3.1 \\
\hline Barley & 1186 & 9.2 & 1.7 & 0.3 & 0.2 & 0.7 & 58.1 & 3.26 & 11.4 & 5.5 & 5.2 & 18 & 50 & 5.2 & 0.2 & 0.1 & 9.9 & 122 & 3.2 \\
\hline Rye & 1096 & 11.0 & 2.1 & 0.3 & 0.3 & 1.0 & 50.0 & 1.2 & 10.1 & 3.3 & 6.8 & 4 & 74 & 1.2 & 0.4 & 0.1 & 1.5 & 113 & 2.0 \\
\hline Triticale & 1404 & 13.1 & 2.1 & 0.4 & 0.2 & 0.9 & $72.3 *$ & - & - & - & - & 1 & 73 & 1.4 & 0.4 & 0.1 & 2.6 & 130 & 3.5 \\
\hline Quinoa & 1317 & 13.2 & 6.1 & 0.7 & 1.6 & 3.3 & 52.2 & 0.0 & 7.0 & - & - & 5 & 184 & 1.5 & 0.3 & 0.3 & 4.5 & 197 & 3.1 \\
\hline Amaranth & 1551 & 13.6 & 7.0 & 1.5 & 1.7 & 2.8 & $58.5 * *$ & 1.7 & 6.7 & - & - & 5 & 82 & 0.9 & 0.1 & 0.2 & 7.6 & 248 & 2.9 \\
\hline Buckwheat & 1434 & 13.3 & 3.4 & 0.7 & 1.0 & 1.0 & $61.5 * *$ & - & 10.0 & - & - & 4 & 30 & 7.0 & 0.1 & 0.4 & 2.2 & 231 & 2.4 \\
\hline
\end{tabular}

$*$ Total carbohydrate by difference. Calculated as the difference between 100 and the weight in grams of (protein + fat + water + ash + alcohol) per $100 g$. $* *$ Available carbohydrate estimated by difference. Calculated as the difference between 100 and the weight in grams of $($ protein + fat + water + ash + alcohol + dietary fibre) per $100 \mathrm{~g}$. 
Subsequently, substitution of oat flour with oat bran at $0 \%, 30 \%, 50 \%, 70 \%$, and $100 \%$ was investigated by Duta and Culetu (2015) for its functional, rheological and wholesome properties. An overall acceptability of 5.6 was accomplished with highest $\beta$-glucan content (4.37\% on dry weight basis) at $100 \%$ incorporation level of oat bran. However, cookies with more darkness and brittleness were produced having enhanced nutritional value at the higher level of supplementation.

Consequently, Arshad et al., (2007) enriched the cookies by substituting wheat flour with a defatted wheat germ (DFWG) at proportions ranging from $0-25 \%$ and its effect on functional and nutritional properties of cookies were analyzed. The DFWG had high total protein content i.e. up to $27.8 \%$ (on dry weight basis) and also abundant in essential amino acids, particularly lysine (2.32 g/100 g). These properties of DFWG produced cookies with highly acceptable quality when fortified at most $15 \%$ level as compared to control wheat flour cookies.

Inglett et al., (2015) prepared sugar cookies using amaranth-oat composites in wheat flour to enhance the nutritional and physical characteristics of the multigrain cookies. They documented that addition of amaranth-oat composites produced cookies which were quite similar to wheat flour cookies in colour, flavour, and texture with enhanced nutritional value. They also showed that the composites had good viscoelastic properties and water holding capacity. Similarly, Altındağ et al., (2015) prepared gluten-free cookie from buckwheat, rice, and corn flour with different proportions and evaluated the effect of transglutaminase (TG) on the cookies quality. The recipe containing $100 \%$ buckwheat had higher protein and ash percentage but the buckwheat-corn cookies were higher in dietary fibre. Moreover, the addition of TG produced softer but higher brittle cookies with enhanced moisture content and spread ratio contrast to cookies without TG. Likewise, Torbica et al., (2012) formulated the glutenfree cookies from buckwheat and rice flour and evaluated the physicochemical and sensory properties. The cookies produced exhibit a gentle flavour and quite reasonable structural qualities. In addition, cookies supplemented with $20 \%$ buckwheat expressed better sensory properties compared to control one.

\section{Sweet bakery products (Cakes) enriched with various cereal grains}

The high fat and sugar content make the cakes a sweet bakery product. The basic materials for formulation of cakes are wheat flour, shortening, leavening agents, sugar, liquid (water, milk, or buttermilk), and eggs. The structural formation which supports these ingredients is important during cake preparation so that cakes of light and delicate should develop. Cakes are two kinds, such as foam type and shortened type (Martins et al., 2017). In foam type cakes (angel food, sponge, chiffon), the foaming and aeration properties of eggs provide the structure and volume to the end product.

On the other hand, the structure of the cakes is developed from the fat-liquid emulsion formed during batter processing in case of shortened type cakes (pound cake, chocolate cake, etc.). The composition of recipes, the aeration and constancy of batters, and the baking and thermal setting processes are the essential parameters to produce good quality cakes with high volume, low crumb firmness, consistent crumb structure, reduced staling rate, and prolonged shelf-life. In this regard, the inclusion or supplementation of alternative flour to wheat flour reduced the staling rate triggering longer life-span (Jongsutjarittam and Charoenrein, 2013). 
Sponge cakes from the polished flour of various hulless barley cultivars were prepared and compared against normal wheat flour cake with respect to rheological, nutritional, structural and sensory properties (Moza and Gujral, 2017). The aforementioned study exposed that the polished hulless barley sponge cake had high viscosity, stable batter and enhanced gelatinization time. The cakes had additionally higher soluble fibre $(\beta$ glucan) and arabinoxylans content extending from $3.4 \%$ to $4.4 \%$ and $0.7 \%$ to $1.1 \%$ respectively. Nevertheless, low protein and high non-starchy polysaccharide (NSP) content of barley flour enhanced the smallsized gas cell formation which amended the crumb structure.

Jongsutjarittam and Charoenrein, (2013) studied the freeze-thawed cake properties by adding 10-20\% waxy rice flour (WRF) into normal wheat flour (WF). They found that the incorporation of WRF in freeze-thawed cake remarkably lower the firmness and dense matrix with higher satisfactoriness than WF cake. The low amylase content and damaged waxy rice starch throughout the swollen wheat starch granules could be the possible cause of above happening.

Gularte et al., (2012) studied the impact of the addition of various fibres like inulin and guar gum as soluble and oat fibre as insoluble constituent both in separate and combination form up to $20 \%$ level to the rice flour in gluten-free layer cakes preparation. The oat fibre -inulin combinations produced cakes with increased specific volume and lighter crust and crumb structure. In contrast, oatguar gum combinations developed cakes with improved batter consistency and crumb hardness. From above discussion, it was stated that the incorporation of fibres increased dietary fibres content in the diet with reduced slowly digestible starch and oat fibre-inulin combinations produced good quality cakes. The diversity of fibre (whole wheat bran, oat bran, cellulose microcrystalline), particles size (50, 80, 250 $\mu \mathrm{m})$ and proportion of replacement $(0 \%, 12$ $\%, 24 \%$, and $36 \%$ level) on functional, rheological and sensory characteristics of batter and layer cake was assessed by Gómez et al., (2010). They showed that the elasticity modulus $\left(\mathrm{G}^{\prime}\right)$ and viscous modulus $\left(\mathrm{G}^{\prime \prime}\right)$ along with batter density increased with increased fibre size with a reduced dough behaviour index. Specifically, cake with bigger sized wheat bran fibre up to $20 \%$ substitution produced the most floppy, elastic and yellow cakes with higher acceptability. However, microcrystalline cellulose added cakes produced similar cakes to that of control.

A multigrain approach for production of gluten-free cakes from cowpea, quinoa, proso millet, chickpeas, flaxseed and white rice flour was developed by Ávila et al., (2017). They studied the nutritional, textural and sensory properties of the above developed multigrain cakes. They demonstrated that the protein content of the composites increased to $3 \%$ whereas minerals like iron, magnesium and zinc increased to $26 \%, 34.2 \%$, and $20 \%$ of RDA when compared with regular cakes. Additionally, from sensory evaluation the cakes proved higher acceptability index (84 $\%)$ making it satiable gluten-free alternative.

\section{Brittle bakery products (biscuits) enrichment with various cereal grains}

Biscuit is a small nutritive baked unleavened cake of crisp, flat, and sweet nature consumed globally. The important elements in biscuit recipes are similar to cake like wheat flour, shortening, sugar, and leavening agents. They have high fat and sugar contents. In view of water percentage in dough preparation, biscuits are categorized as soft (cookies) or hard (crackers). The soft dough is prepared with less water and reasonably high levels of 
fat and sugar whereas hard dough contains high water and comparatively less fat and sugar. Furthermore, the soft dough has low extensibility and the hard dough is tough and extensible (Martins et al., 2017).

In recent times, the demand for composite flour based health-oriented baked products such as biscuits, snacks or crackers are in high among consumer. Cukelj et al., (2017) prepared biscuits from whole wheat, rye, oat, and barley mixed with flaxseed at $10 \%$ (on weight basis) and measured the physicochemical, antioxidant, and tangible qualities along with oxidative stability during storage. They documented that proper combination of flaxseed with these flours produced acceptable biscuits with elevated phenolics. Moreover, the textural properties significantly influenced by the quality of cereal flour added and could be stored for three months at room temperature afterwards oxidative stability decreased.

In a study carried by Vujić et al., (2015), either $30 \%$ of the wheat flour was substituted with some wholesome flour from barley, buckwheat, oat, amaranth or soy or $15 \%$ of wheat flour substituted by apple or oat fibre for the production of multigrain biscuits. The impact of the inclusion of all these flours on nutritional, functional and sensory properties of the end product was evaluated by the research group. They revealed that the fortification elevated the macronutrient content, dietary fibre content and protein content in the final product. However, the soy and amaranth inclusion generated products with reduced readily digestible starch (RDS) and total starch (TS) compared to control sample although oat and apple supplementation improved the glycemic response. Furthermore, all the formulations substantially increased the sensory acceptability in assessment to control wheat biscuit. Regarding fibre related nutrition claims, Sudha et al., (2007) developed biscuits by adding bran from wheat, rice, oat and barley to whole wheat flour dough and evaluated the rheological and biscuit making quality. They reported that the water absorption capacity of the bran mixed composite dough increased with increased level of substitution (0-40 \%) along with reduced dough extensibility. In addition, highly favourable biscuits could be produced when whole wheat flour substituted with 30 $\%$ oat bran or $20 \%$ barley bran. Similarly, Villemejane et al., (2013) produced functional fibre rich biscuits from different fibres (oat bran, barley bran, and guar gum) and studied their effects on dough hydration as well sensory attributes. They showed that the dough consistency increased with total dietary fibre and reduced sugar content. A computer vision system approach was adopted by Lara et al., (2011) in order to assess the physical, nutritional quality of corn biscuits during baking in real time and different oven temperatures. The colour, crust appearance and volume rise could be easily demarcated using the computer vision system which made the approach a useful tool.

Pseudo-cereals like buckwheat, amaranth and quinoa also fortified with biscuits and snacks to produce pseudo-cereal derived bakery products. Wójtowicz et al., (2013) demonstrated the development of nutritionally enriched corn-buckwheat biscuit by supplementing to a level not higher than $30 \%$ with good consumer acceptability. Baljeet et al., (2010) effectively fused buckwheat flour into polished wheat flour biscuits not higher than $20 \%$ to produced improved health quality biscuits with adequate tangible properties. Likewise, in another study by Filipčev et al., (2011) claimed there was substantial upsurge in the nutritional quality (protein, dietary fibre, total polyphenols, antioxidant and chelating activity and macro and microelements) of wheat biscuits when 
prepared with buckwheat at $10 \%, 20 \%, 30$ $\%$, and $40 \%$ level. They also exhibited that the biscuits created by mixing of $20 \%$, and $30 \%$ have remarkable acceptability score (6.71 and 6.20 respectively).

In last decades, individuals demand foodstuffs with better quality and health benefits plus minimally processed food created new challenges for the food industry. Baked products are widely consumed staple food among the greater part of population throughout the world and the most suitable carrier of dietary fibre and antioxidative compounds in the diet. So the fortification of bakery products with fibre rich cereals and pseudo-cereals has gotten restored enthusiasm due to resources other than cereal products being desired after and researched. In this sense, the paper has reviewed the recent advances in the above field and has documented the use of a diversified group of cereals and pseudocereals for production of nutritionally rich baked products. Several studies also emphasized on the functional and rheological behaviour of dough and batter and their interaction with the raw material, especially with fibre component. Many of the researchers had proposed that enrichment of cereals and pseudo-cereals and their fibres substantially enhanced the gluten network with improved shape, volume and texture of the end products.

In addition, the multigrain bakery products produced from various cereal grains exhibited better consumer acceptability throughout the world. Looking into above advantages, several food sectors have inspired and started this lucrative business over the last two decades. Therefore, inter-industry connections and research-oriented systems have to be addressed towards the development of healthoriented functional multigrain bakery products.

\section{Acknowledgments}

The authors would like to thank Agricultural and Food Engineering Department, Indian Institute of Technology, Kharagpur, for providing infrastructure, financial aid and support throughout the project dissemination.

\section{References}

Adom, K. K., Sorrells, M. E., and Liu, R. H. (2003). Phytochemical profiles and antioxidant activity of wheat varieties. Journal of Agricultural and Food Chemistry, 51, 7825-7834.

Akhtar, S., Anjum, F. M., and Anjum, M. A. A. (2011). Micronutrient fortification of wheat flour: recent development and strategies. Food Research International, 44, 652-659.

Altındağ, G., Certel, M., Erem, F., and İlknur Konak, Ü. (2015). Quality characteristics of gluten-free cookies made of buckwheat, corn, and rice flour with/without transglutaminase. Revista de Agaroquimica y Tecnologia de Alimentos, 21(3), 213-220.

Alvarez-Jubete, L., Wijngaard, H., Arendt, E. K., and Gallagher, E. (2010). Polyphenol composition and in vitro antioxidant activity of amaranth, quinoa buckwheat and wheat as affected by sprouting and baking. Food chemistry, 119(2), 770-778.

Arshad, M. U., Anjum, F. M., and Zahoor, T. (2007). Nutritional assessment of cookies supplemented with defatted wheat germ. Food chemistry, 102(1), 123-128.

Ávila, B. P., Braganca, G. C. M., Rockenbach, R., Alves, G. D., Monks, J., Gularte, M. A., and Elias, M. C. (2017). Physical and sensory characteristics of cake prepared with six whole-grain flours. Journal of Food Measurement and Characterization, 1-7. 
Baljeet, S. Y., Ritika, B. Y., and Roshan, L. Y. (2010). Studies on functional properties and incorporation of buckwheat flour for biscuit making. International Food Research Journal, 17(4).

Baumgartner, B., Özkaya, B., Saka, I., and Özkaya, H. (2018). Functional and physical properties of cookies enriched with dephytinized oat bran. Journal of Cereal Science. 80, 24-30.

Betoret, E., Betoret, N., Vidal, D., and Fito, P. (2011). Functional foods development: trends and technologies. Trends in Food Science and Technology, 22(9), 498508.

Bigliardi B., Galati F., (2013). Innovation trends in the food industry: The case of functional foods. Trends in Food Science and Technology, 31, 118-129.

Chauhan, A., Saxena, D. C., and Singh, S. (2015). Total dietary fibre and antioxidant activity of gluten free cookies made from raw and germinated amaranth (Amaranthus spp.) flour. LWT-Food Science and Technology, 63(2), 939-945.

Cheng, Y. F., and Bhat, R. (2016). Functional, physicochemical and sensory properties of novel cookies produced by utilizing underutilized jering (Pithecellobium jiringa Jack.) legume flour. Food Bioscience, 14, 54-61.

Chlopicka, J., Pasko, P., Gorinstein, S., Jedryas, A., and Zagrodzki, P. (2012). Total phenolic and total flavonoid content, antioxidant activity and sensory evaluation of pseudocereal breads. LWT-Food Science and Technology, 46(2), 548-555.

Cukelj, N., Novotni, D., Sarajlija, H., Drakula, S., Voucko, B., and Curic, D. (2017). Flaxseed and multigrain mixtures in the development biscuits of functional. LWT-Food Science and Technology, 86, 85-92.
Dauda, A. O., Abiodun, O. A., Arise, A. K., and Oyeyinka, S. A. (2017). Nutritional and consumers acceptance of biscuit made from wheat flour fortified with partially defatted groundnut paste. LWT-Food Science and Technology, 90, 265-269.

De la Hera, E., Ruiz-París, E., Oliete, B., and Gómez, M. (2012). Studies of the quality of cakes made with wheat-lentil composite flours. LWT-Food Science and Technology, 49(1), 48-54.

Dhingra, S., and Jood, S. (2002). Organoleptic and nutritional evaluation of wheat breads supplemented with soybean and barley flour. Food chemistry, 77(4), 479-488.

Duta, D. E., and Culetu, A. (2015). Evaluation of rheological, physicochemical, thermal, mechanical and sensory properties of oat-based gluten free cookies. Journal of Food Engineering, 162, 1-8.

Dziki, D., Różyło, R., Gawlik-Dziki, U., and Świeca, M. (2014). Current trends in the enhancement of antioxidant activity of wheat bread by the addition of plant materials rich in phenolic compounds. Trends in Food Science and Technology, 40(1), 48-61.

Filipčev, B., Šimurina, O., Sakač, M., Sedej, I., Jovanov, P., Pestorić, M., and Bodroža-Solarov, M. (2011). Feasibility of use of buckwheat flour as an ingredient in ginger nut biscuit formulation. Food Chemistry, 125(1), 164-170.

Giménez-Bastida, J. A., Piskula, M. K., and Zieliñski, H. (2015). Recent advances in processing and development of buckwheat derived bakery and nonbakery products-a review. Polish Journal of Food and Nutrition Sciences, 65(1), 9-20.

Gómez, M., Moraleja, A., Oliete, B., Ruiz, E., and Caballero, P. A. (2010). Effect of 
fibre size on the quality of fibreenriched layer cakes. LWT-Food Science and Technology, 43(1), 33-38.

González-Sarrías A., Larrosa M., GarcíaConesa M.T., Tomás- -Barberán F.A., Espín J.C., (2013). Nutraceuticals for older people: facts, fi ctions and gaps in knowledge. Maturitas, 75, 313-34

Grains and Nutrition (2012). Retrived from https://www.glnc.org.au/grains-

2/grains-and-nutrition.

Gularte, M. A., de la Hera, E., Gómez, M., and Rosell, C. M. (2012). Effect of different fibers on batter and gluten-free layer cake properties. LWT-Food science and technology, 48(2), 209-214.

Gunenc, A., Tavakoli, H., Seetharaman, K., Mayer, P. M., Fairbanks, D., and Hosseinian, F. (2013). Stability and antioxidant activity of alkyresorcinols in breads enriched with hard and soft wheat brans. Food Research International, 51, 571-578.

Gupta, M., Bawa, A. S., and Semwal, A. D. (2011). Effect of barley flour blending on functional, baking and organoleptic characteristics of high- fiber rusks. Journal of food processing and preservation, 35(1), 46-63.

Henry, R. J., Rangan, P., and Furtado, A. (2016). Functional cereals for production in new and variable climates. Current opinion in plant biology, 30, 11-18.

Hidalgo, A., Ferraretto, A., De Noni, I., Bottani, M., Cattaneo, S., Galli, S., and Brandolini, A. (2018). Bioactive compounds and antioxidant properties of pseudocereals-enriched water biscuits and their in vitro digestates. Food Chemistry, 240, 799-807.

Holtekjølen, A. K., Bævre, A. B., Rødbotten, M., Berg, H., and Knutsen, S. H. (2008). Antioxidant properties and sensory profiles of breads containing barley flour. Food Chemistry, 110(2), 414-421.

Hooda, S., and Jood, S. (2005). Organoleptic and nutritional evaluation of wheat biscuits supplemented with untreated and treated fenugreek flour. Food Chemistry, 90(3), 427-435.

Hung, P. V., Maeda, T., Miyatake, K., and Morita, N. (2009). Total phenolic compounds and antioxidant capacity of wheat graded flours by polishing method. Food Research International, 42, 185-190.

Inglett, G. E., Chen, D., and Liu, S. X. (2015). Physical properties of gluten-free sugar cookies made from amaranth-oat composites. LWT-Food Science and Technology, 63(1), 214-220.

Jongsutjarittam, N., and Charoenrein, S. (2013). Influence of waxy rice flour substitution for wheat flour on characteristics of batter and freezethawed cake. Carbohydrate polymers, 97(2), 306-314.

Khattak, A. B., Zeb, A., Bibi, N., Khalil, S. A., and Khattak, M. S. (2007). Influence of germination techniques on phytic acid and polyphenols content of chickpea (Cicer arietinum L.) sprouts. Food chemistry, 104(3), 1074-1079.

Koletta, P., Irakli, M., Papageorgiou, M., and Skendi, A. (2014). Physicochemical and technological properties of highly enriched wheat breads with wholegrain non wheat flours. Journal of Cereal science, 60(3), 561-568.

Lara, E., Cortés, P., Briones, V., and Perez, M. (2011). Structural and physical modifications of corn biscuits during baking process. LWT-Food Science and Technology, 44(3), 622-630.

Mäkinen, O. E., and Arendt, E. K. (2012). Oat malt as a baking ingredient $-\mathrm{A}$ comparative study of the impact of oat, barley and wheat malts on bread and 
dough properties. Journal of cereal science, 56(3), 747-753.

Marti, A., Cardone, G., Pagani, M. A., and Casiraghi, M. C. (2018). Flour from sprouted wheat as a new ingredient in bread-making. LWT-Food Science and Technology, 89, 237-243.

Martins, Z. E., Pinho, O., and Ferreira, I. M. P. L. V. O. (2017). Food industry byproducts used as functional ingredients of bakery products. Trends in Food Science and Technology, 67, 106-128.

McKevith, B. (2004). Nutritional aspects of cereals. Nutrition Bulletin, 29(2), 111142.

Moza, J., and Gujral, H. S. (2017). Influence of barley non-starchy polysaccharides on selected quality attributes of sponge cakes. LWT-Food Science and Technology, 85, 252-261.

Poutanen, K., Sozer, N., and Della Valle, G. (2014). How can technology help to deliver more of grain in cereal foods for a healthy diet? Journal of Cereal Science, 59(3), 327-336.

Qiang, W. A. N. G., Liu, H. Z., Shi, A. M., Hui, H. U., Li, L. I. U., Li, W. A. N. G., and $\mathrm{Yu}, \mathrm{H}$. W. (2017). Review on the processing characteristics of cereals and oilseeds and their processing suitability evaluation technology. Journal of Integrative Agriculture, 16(12), 28862897.

Ragaee, S., Guzar, I., Dhull, N., and Seetharaman, K. (2011). Effects of fiber addition on antioxidant capacity and nutritional quality of wheat bread. LWT-Food Science and Technology, 44(10), 2147-2153.

Rajiv, J., and Soumya, C. (2015). Chemical, rheological and nutritional qualities of sugar snap cookies as influenced by the addition of multigrains. Journal of Food Measurement and Characterization, 9(2), 135-142.
Rasane, P., Jha, A., Sabikhi, L., Kumar, A., and Unnikrishnan, V. S. (2015). Nutritional advantages of oats and opportunities for its processing as value added foods-a review. Journal of food science and technology, 52(2), 662-675.

Rieder, A., Holtekjølen, A. K., Sahlstrøm, S., and Moldestad, A. (2012). Effect of barley and oat flour types and sourdoughs on dough rheology and bread quality of composite wheat bread. Journal of Cereal science, 55(1), 44-52.

Romero, A. L., Romero, J. E., Galaviz, S., and Fernandez, M. L. (1998). Cookies enriched with psyllium or oat bran lower plasma LDL cholesterol in normal and hypercholesterolemic men from Northern Mexico. Journal of the American College of Nutrition, 17(6), 601-608.

Sanz-Penella, J. M., Wronkowska, M., SoralSmietana, M., and Haros, M. (2013). Effect of whole amaranth flour on bread properties and nutritive value. LWTFood Science and Technology, 50(2), 679-685.

Serpen, A., Gokmen, V., and Mogol, B. A. (2012). Effects of different grain mixtures on Maillard reaction products and total antioxidant capacities of breads. Journal of Food Composition and Analysis, 26, 160-168.

Sharma, P., and Gujral, H. S. (2014). Cookie making behavior of wheat-barley flour blends and effects on antioxidant properties. LWT-Food Science and Technology, 55(1), 301-307.

Shewry, P. R., Charmet, G., Branlard, G., Lafiandra, D., Gergelyd, S., Salgo, A., et al., (2012). Developing new types of wheat with enhanced health benefits. Trends in Food Science and Technology, 25, 70-77.

Sivam, A. S., Sun-Waterhouse, D. X., Waterhouse, G. I. N., Quek, S. and Perera, C. O. (2011). Physicochemical 
properties of bread dough and finished bread with added pectin fiber and phenol antioxidants. Journal of Food Science, 76, H97-H107.

Škrbić, B., Milovac, S., Dodig, D., and Filipčev, B. (2009). Effects of hull-less barley flour and flakes on bread nutritional composition and sensory properties. Food Chemistry, 115(3), 982-988.

Souci, S. W., Fachmann, W., and Kraut, H. (1981). Food composition and nutrition tables 1981/82. (Ed. 2). CRC Press, USA.

Stokić, E., Mandić, A., Sakač, M., Mišan, A., Pestorić, M., Šimurina, O.,... and Sedej, I. (2015). Quality of buckwheatenriched wheat bread and its antihyperlipidemic effect in statin treated patients. LWT-Food Science and Technology, 63(1), 556-561.

Sudha, M. L., Vetrimani, R., and Leelavathi, K. (2007). Influence of fibre from different cereals on the rheological characteristics of wheat flour dough and on biscuit quality. Food chemistry, 100(4), 1365-1370.

Sui, X., Zhang, Y., and Zhou, W. (2016). Bread fortified with anthocyanin-rich extract from black rice as nutraceutical sources: Its quality attributes and in vitro digestibility. Food chemistry, 196, 910-916.

Torbica, A., Hadnađev, M., and Hadnađev, T. D. (2012). Rice and buckwheat flour characterisation and its relation to cookie quality. Food Research International, 48(1), 277-283.
Verardo, V., Glicerina, V., Cocci, E., Frenich, A. G., Romani, S., and Caboni, M. F. (2018). Determination of free and bound phenolic compounds and their antioxidant activity in buckwheat bread loaf, crust and crumb. LWT-Food Science and Technology, 87, 217-224.

Villemejane, C., Roussel, P., Berland, S., Aymard, P., and Michon, C. (2013). Technological and sensory tools to characterize the consistency and performance of fibre-enriched biscuit doughs. Journal of cereal science, 57(3), 551-559.

Vujić, L., Čepo, D. V., and Dragojević, I. V. (2015). Impact of dietetic tea biscuit formulation on starch digestibility and selected nutritional and sensory characteristics. LWT-Food Science and Technology, 62(1), 647-653.

Wójtowicz, A., Kolasa, A., and Mościcki, L. (2013). Influence of buckwheat addition on physical properties, texture and sensory characteristics of extruded corn snacks. Polish Journal of Food and Nutrition Sciences, 63(4), 239-244.

Zieliński, H., Ceglińska, A., and Michalska, A. (2008). Bioactive compounds in spelt bread. European Food Research and Technology, 226(3), 537.

Zucco, F., Borsuk, Y., and Arntfield, S. D. (2011). Physical and nutritional evaluation of wheat cookies supplemented with pulse flours of different particle sizes. LWT-Food Science and Technology, 44(10), 20702076.

\section{How to cite this article:}

Sunil Manohar Behera and Srivastav, P.P. 2018. Recent Advances in Development of Multi Grain Bakery Products: A Review. Int.J.Curr.Microbiol.App.Sci. 7(05): 1604-1618. doi: https://doi.org/10.20546/ijcmas.2018.705.190 